\title{
9 Plurisexualities and consensual non-monogamies
}

\section{Challenging normativities in Italy}

\author{
Nicole Braida
}

\section{Introduction}

Some studies suggest a relatively high percentage of consensual nonmonogamous practices and/or relational preferences among bisexual people (Klesse, 2007; Page, 2004; Robinson, 2013). My study of theories and practices of consensual non-monogamy ${ }^{1}$ in Italy confirms this. Indeed, among the 60 people I interviewed (who were not selected on the basis of sexual or romantic orientation), 27 defined themselves as plurisexual (24 as bisexual and/or pansexual, and three as heteroflexible). This number rises to 32 if we include those who defined themselves as "questioning" or did not use any label.

Bisexual identities have been marginalised for years within the LGBT movement in Italy. The main LGBT associations have contributed to this erasure, as has also happened in other countries (cf. Maliepaard, 2017). Only in recent years have local groups and associations emerged that are dedicated to bisexualities. Mondo Bisex: Coordinamento nazionale per la visibilità bisessuale (Bisex World: National Coordination for Bisexual Visibility) has been active since 2016, and was formed by activists from different local groups. In addition, the first Italian $\mathrm{Bi}+$ Pride was held in Padua in 2017.

Italian politics displays a conservative attitude, especially in relation to family values and family structures, both of which are represented and strengthened by the country's familialist welfare regime (Gusmano, 2018). Furthermore, the legislation that regulates partnering in Italy is shaped by heteronormativity and compulsory monogamy. Under 2016's Cirinnà Law, marriage remains accessible exclusively to couples consisting of a woman and a man, while same-sex couples have access only to civil unions, and no recognition is provided outside of couple relationships. In this context, both plurisexualities and non-monogamies suffer from delegitimisation and stigmatisation (Gusmano, 2018).

In this chapter I focus on the narratives of participants who identify as plurisexual. First, I describe a number of key concepts: binegativity, bi-erasure, compulsory monogamy, binormativity, and polynormativity. 


\section{Nicole Braida}

I then present the methods used before discussing some of the participants' narratives regarding the intersection of bisexuality and consensual nonmonogamous relational practices. Next, I highlight narratives around experiences of binegativity, experiences in LGBT spaces, and the roles of the polyamorous community. Finally, I use the concepts of binormativity and polynormativity to investigate the potential conflicts between the two identities/practices, and explore potential strategies to overcome these conflicts.

\section{Theoretical definitions}

\section{Binegativity and bi-erasure}

"Binegativity" refers to all negative beliefs or behaviours related to plurisexual orientations (Klesse, 2011). The term "biphobia" is used more often to convey the same meaning, but similarly to the term "homophobia", it makes an explicit reference to fear ("phobia"). For this reason, contemporary scholarship on bisexualities prefers the term "binegativity" because it is more neutral regarding the origins of the attitude (cf. Baumgartner, 2017). One of the ways in which binegativity is expressed is through the reinforcement and reproduction of negative stereotypes associated with plurisexual orientations, such as the depiction of plurisexual people as unreliable, necessarily unfaithful, spreaders of sexually transmitted infections, unstable, and/ or confused (Baumgartner, 2017; Eisner, 2013; Ochs, 1996).

Another specific form of binegativity is bi-erasure, which can be defined as the set of behaviours that help to obscure the visibility or question the validity of plurisexual orientations - for example, by assimilating them into either homosexuality or heterosexuality, or by seeing them as a phase or a fashion (Eisner, 2013). Living in a social context where binegative attitudes are pervasive, plurisexual people often internalise these attitudes. People who have internalised binegativity are inclined to interpret their own sexualromantic orientations and sexual and/or romantic behaviours through the lens of binegativity (Baumgartner, 2017; Meyer, 2003; Ochs, 1996).

\section{Compulsory monogamy}

Toft and Yip (2018, p. 245) define compulsory monogamy as "the dominant aspirational norm that underpins the popular construction of 'committed' and 'faithful' intimate relationships". As the two authors highlight, compulsory monogamy, in association with "compulsory coupledom" (Wilkinson, 2013), continues to define the norm for intimate relationships that can be considered " 'authentic', 'committed', and 'fulfilling'” (Toft and Yip, 2018, p. 235). In conjunction with heteronormativity, this gives rise to a variety of cultural, institutional, and legal mechanisms that prioritise a very specific 
relational form over others: a sustainable and exclusive sexual and affective relationship between two individuals, preferably consisting of a man and a woman. Same-sex relationships have recently received greater recognition, but they still need to demonstrate this exclusive and sustainable character (cf. Gustavson, 2009).

\section{Binormativity and polynormativity}

People who are both plurisexual and non-monogamous also have to face specific difficulties that can arise from the intersection of the two identities/practices. The analysis presented in this chapter is influenced by the perspective of intersectionality, which highlights the need to consider the intersections between different axes of oppression (cf. Cooper, 2016). In this case, the focus is on the axes of sexual orientation and relational practices; I have made a conscious choice to set aside other axes in this chapter. This focus on sexual orientation and relational practices was also used by Gusmano (2018) in her article on the coming out of bisexual and polyamorous people in Italy. Here I highlight binormativity and polynormativity, as these are the core concepts through which to analyse potential conflicts between the two communities.

Binormativity can be defined as "the normalisation of a certain standard of bisexuality against which all other forms of bisexuality are measured" (Del Castillo, 2015, p. 10). This phenomenon refers to the strategy, largely adopted by the mainstream bisexual movement, of rejecting the commonest stereotypes of bisexuality with what Eisner (2013, p. 40) calls the "'that's not true!' formula". For example, in response to the stereotype that portrays bisexual people as "slutty, promiscuous or inherently unfaithful" (Eisner, 2013 , p. 41), the mainstream bisexual movement often highlights bisexual people's success in maintaining happy, exclusive relationships for a long time, and rejects the equation between bisexuality and sexual promiscuity. While this may absolutely be true for a number of bisexual people, this "defence" of bisexuality also risks imprisoning the image of the bisexual within a standard of the "normal" and "good" bisexual, thereby excluding all the bisexual people who do not fit that standard (Eisner, 2013; see also Gurevich et al., 2007; Maliepaard, 2017).

An analogous phenomenon within the polyamorous community is "polynormativity", defined as "any discourse defending polyamory as the right, best, or superior way of intimate relating" (Ferrer, 2018, p. 11). The main strategy behind this representation, both in the media and in polyamorous groups, consists of distancing oneself from other forms of nonmonogamy, especially those that focus on sexual experimentation and promiscuity (casual sex, swinging) or are not "ethical" (infidelity). Instead, the focus is placed on what Wilkinson (2010) calls "polyromanticism", that is, a narrative of polyamory centred on love and intimacy. 


\section{Nicole Braida}

\section{Methods}

My theoretical approach is influenced by critical theory and constructionist research (cf. Guba \& Lincoln, 1994). Proponents of critical theory see research as a tool for social change, and they aim to give a voice to people who are excluded from dominant discourses (cf. Guba \& Lincoln, 1994; Keso, Lehtimäki, \& Pietiläinen, 2009). The main research purpose of constructionists is to present alternative interpretations of reality, constantly trying to question the taken-for-granted, and making visible the structures and dynamics of power (Keso et al., 2009).

My research, which I carried out as part of my three-year doctoral project (October 2016 to September 2019), took a mostly inductive approach and relied on an insider perspective, since I had already been familiar with the Italian polyamorous network for around five years.

\section{Participants}

The 32 plurisexual people in my sub-sample were aged between 23 and 51 at the time of the interview. They were all Italian and white, and they were mostly middle or higher educated (all had at least secondary education, more than two-thirds had tertiary education). Regarding their gender identities, eight participants were non-binary - that is, they did not identify as either men or women -18 were women, and six were men. There was quite a variety in their understandings of romantic orientation: 19 identified as polyamorous; one person used two terms, "polyamorous" and "ethical nonmonogamous"; another person reported oscillating between "polyamory" and "relationship anarchy"; another respondent preferred to say that she had decided to have polyamorous relationships but refused the polyamorous identity; five identified as relationship anarchists; one used either "relationship anarchist" or "polyamorous", depending on to whom he was speaking; three people preferred to use more generic terms, such as "nonmonogamous"; and finally, one person preferred not to define her relational orientation in any way other than "queer".

\section{Recruitment strategies}

The criteria for recruitment were that interview participants should have had at least two relationships at the same time for at least six months with the knowledge and consent of all the people involved.

I tried to recruit people from both inside and outside the polyamorous community. Recruitment inside the community followed two strategies: (1) online, through calls for participants circulated in local polyamorous groups, and by directly contacting people who had ideas or experiences that I considered useful to diversify my sample; and (2) in person, during participation in local meetings. 
To reach people who were not insiders of the polyamorous community, I activated my informal networks in communities that had some intersections with the polyamorous community, such as queer spaces, kinky/BDSM/sexpositive communities, and LGBT+ groups. Finally, I also used snowball sampling to recruit people from different networks.

\section{Instruments and analysis}

Although I also used other methods in my doctoral research (the analysis of online discourses, and participant observation), in this chapter I limit the discussion to the results of the interviews.

I officially began the fieldwork in October 2017 and finished it in July 2018. I conducted observant participation and/or interviews in ten cities/ regions: Turin, Rome, Bologna, Padua, Florence/Tuscany, Milan, Genoa, Sardinia, Naples, and Palermo. The interviews were semi-structured, conducted in person by me, and audio-recorded. In all cases I asked the interviewees to choose a place that was comfortable for them and not too noisy. Most of the interviews were conducted in cafes or private homes. They lasted between 40 and 150 minutes, but most were around 90 minutes in duration. All the interviews were transcribed verbatim before analysis. I used Dedoose data analysis software to code the interview data. I organised the analysis of the material using codes and subcodes, then I analysed each code separately with the help of schemes and conceptual maps, which were followed by further schematisations. All names are pseudonyms.

\section{Results}

\section{Plurisexualities and consensual non-monogamies: Blurring boundaries}

Since one of the most persistent stereotypes about bisexuality revolves around the notion that bisexual people must have relationships with more than one sex or gender to feel complete and satisfied (Rust, 2003), one might expect it to have been the plurisexual orientation of my interviewees that had led them to non-monogamy. On the contrary, though, just three of my interviewees reported a narrative that approached this pattern. For example, Marta (42, pansexual cis woman) thought that her orientation had facilitated non-monogamous living from the beginning of the relationship: "I felt bisexual and I said this immediately, and therefore this already opened up the discussion a little in the couple".

Instead, there were far more narratives that presented the exploration of plurisexuality as running parallel with the exploration of consensual nonmonogamy, or presented the exploration of non-monogamy as an incentive for the exploration of plurisexuality. For two people, Guido and Pau, the exploration of plurisexuality had gone hand in hand with the exploration not only of consensual non-monogamy, but also of gender identity. 
I consider [the discovery of polyamory] a milestone in my life, that is: There is really a before and an after. If I saw my wardrobe as it was before and as it is after, that is ... ${ }^{3}$ Later, in a month, I questioned everything: gender identity, relationship, aaaand ... sexual orient ... - better, sexual, I had never formalised it but it had never been a problem for me to think that I could like men sexually - affectively I had never ... evaluated, I had never reasoned about it.

(Guido, 30, pansexual genderfluid)

In Guido's narrative, the discovery of polyamory clearly divided their life in two. They highlighted how their life had changed completely, questioning not only their relationship preferences but also their gender identity (previously, they had never questioned their male identity, but now they realised they were genderfluid), their gender performance (they changed their wardrobe), and their sexual and in particular affective orientation (from heterosexual to pansexual).

Pau said:

Meanwhile I understand, in that period then, to be attracted also to men, but I experiment sexually with women, with which I am, in a series of ways, helped a lot, precisely, by [a] bisexual and polyamorous girl, whoooo makes me experiment with a whole series of sexual modalities, [...] a whole series of ... cross-dressing, and ... ooof ... role play, experimentation, which I had only sketched before.

(Pau, 25, pansexual non-cis)

In Pau's narrative, her polyamorous experience opened the way for her first to question her sexual orientation and then to question her gender identity. At the time of the interview, she identified simply as "non-cis", but later she began to use female pronouns and started her transition.

If we turn now to the group of people who read their own discovery of consensual non-monogamy as antecedent to their exploration of plurisexuality, Amedeo told me that the experience of consensual non-monogamy had led him also to question his romantic orientation. In particular, through polyamorous experiences, he realised he could love men too:

The wonderful thing is that there has never been anything [sexual] between me and that boy [...] but I have discovered that I love him. And it was very nice, it was a shock, no one had ever told me that you could love someone like that.

(Amedeo, 35, questioning cis man)

In this regard, even Filippo - who continued to call himself homosexual, and for this reason is not included in the subsample - told me that the experience 
of polyamory had been so intense that it had led him to consider having an emotional relationship with a woman for the first time:

First, yes, maybe it happened to me to make out with a girl, but I wouldn't have thought of establishing a relationship with a girl, because I followed this prevailing stream, so my declared homosexuality meant that I ... had a lot of male sexual partners.

(Filippo, 48, gay cis man)

These findings mirror a more general attitude among many of my participants. Indeed, with their discovery of consensual non-monogamies, many respondents emphasised a passage from definitions that were rigid and had solid boundaries to definitions that were more nuanced, pluralised, and multifaceted. These narratives concerned not only sexual and romantic orientations, but also the distinction between significant and non-significant relationships, the definition of love, and in some cases also gender identities. They can be read as "postmodern stories" (cf. Plummer, 1995), because they move towards the abandonment of a "linear, one-dimensional" and universal model to embrace a more nuanced, complex, and context-specific idea of progress (Simon, 1996, p. 25). Above all, these participants began to question dichotomies such as heterosexual/homosexual, love/not love, and man/woman (cf. Ochs, 1996).

\section{Experiences of binegativity}

People who are both plurisexual and non-monogamous face specific negativities due to their position in between conditions that are seen as opposite and mutually exclusive in mainstream discourse, such as homosexual/heterosexual or radical/mainstream (Gusmano, 2018; Rambukkana, 2004). In Rambukkana's (2004, p. 144) words, their "social mantles" have a "liminal nature". In this position, labels and definitions can be perceived as a strategy to reaffirm oneself, but not necessarily in fixed or immutable ways (cf. Robinson, 2013).

Manuel started from an episode where a stranger accused him of "defining too much" to reaffirm the importance of self-definition as a tool of empowerment against trans- and binegativity:

The person who approached me [...] said: 'Well, [...] you are a person who defines himself so much [...], you can't feel good if you define yourself so much, you are one who does not let go.' And there, really, it was the first time I imposed, I really put my identity, my wall in front of someone, saying: 'I decide for myself, because in my experience I realised that if I don't do it, the other thousand relationships do it in my place'. It could be a big thing like [my former partner], that then, out 
of the couple, the game, the sadomasochism, aaand ... a thousand other things and practices [...] he tells me: 'Oh well, you're sick', or it could be, later, in a relationship with a very serene person, when speaking of my sexuality, they say: 'You believe you are bisexual', that is, that hint ... it resonated with me as: 'Until proven otherwise', which is something that has fucking annoyed me since I developed, basically.

(Manuel, 32, bisexual non-binary trans man)

Other respondents revealed a hesitance about calling themselves bisexual out of the fear that they lacked experience or that their attraction to different genders was too unbalanced. For example, Serena (28, heteroflexible cis woman) had four male partners at the time of the interview, but she also had a "special friendship" with a girl with whom she had had sexual interactions and had also lived for a period; yet this seemed to her not to be "enough" for her to be called "truly bisexual". This feeling of inadequacy is a sign of the internalisation of a definition of bisexuality that envisages an equal degree of romantic and sexual attraction to men and women as a necessary condition (cf. Maliepaard, 2017).

However, since the 1990s a more inclusive definition of bisexuality has spread among bisexual movements, both with respect to non-binary identities and with regard to the possibility of experimenting with different degrees and modes of attraction to different genders (e.g. Ochs \& Rowley, 2009). As Eisner (2013, pp. 21-22) points out, the strength of this definition "is in the way it enables anyone who wants to identify as bisexual to do so (In other words, it reassures people)".

In my view, another effect of bi-erasure (understood as the tendency to ignore, falsify, or minimise the existence of bisexuality) is that plurisexual people who are in relationships with people of a different gender are read as heterosexual by society (cf. Gusmano, 2018; McLean, 2008) because bisexuality is normally not considered as a hypothesis. This effect is also due to the tendency of Western societies to organise the world into dichotomies (Klesse, 2005). In this regard, Attilio remarked on the importance of coming out in a situation of social invisibility:

If the occasion happens I say it, also because, being ... pan, but having currently only relationships with women, that is I become ... invisible. So, I mean, I really want to say it.

(Attilio, 42, pansexual cis man)

Some of the participants in Robinson's (2013) study suffered similar frustration about passing as straight because they were in a relationship with a man. This is a wider problem for plurisexual identities that makes plurisexual people feel they must constantly reaffirm their sexuality through their behaviour (cf. Klesse, 2007). 


\section{Experiences in LGBT spaces}

Binegativity in LGBT spaces is a well-known problem within bisexual studies (e.g. Ault, 1994; Baumgartner, 2017), which can have repercussions for plurisexual people's ability to engage in relationships and for their relational wellbeing in general, due to the stereotype that bisexual people are not reliable partners (see Baumgartner, 2017; Klesse, 2011). Some people in my subsample had experienced binegativity that aimed to invalidate and erase their orientation:

The unique problems I had with regard to the relationship discourse are ... stories of rather heavy bullying by lesbians who told me: 'Because you didn't find anybody who licks you well', aaaaand ... [this] with my girlfriend at my side ... [giggle] [...], and then by a girl who was part of [a famous Italian LGBT association] that told me I'm sick.

(Emilia, 30, bisexual cis woman)

The episode reported by Emilia was particularly emotionally violent, because the person with whom she was interacting not only questioned her orientation but also attributed the cause of her non-conversion to lesbianism to her partner's lack of sexual skill, in her partner's presence.

I will always remember the first time I arrived [at a self-help group for gay men] [...] When you have to do the presentation, I said: 'Well, I'm Valerio, blah blah blah ... I'm bisexual', and the coordinator told me: 'Quiet, that is ... is a phase, it does not exist!' ... and I thought: 'Fuck, I come here ...' that is, now, it was not so ... it was more important to be accepted as gay, so I said: 'Okay, if he says that it doesn't exist ...'

(Valerio, 42, bisexual cis man)

In Valerio's case, the invalidation of his orientation came from the coordinator of the gay self-help group he was attending, and this led to his internalisation of the bi-erasure; he reclaimed his self-definition as bisexual only 15 years later.

\section{Roles of the polyamorous community}

Some people emphasised the important role of the polyamorous community, which provided a space in which to encounter and experiment with practices outside heteronormativity, compulsory monogamy, and cisnormativity. For example, Irene told me:

I remember that it was in July that I went to the first meeting with the polyamorous community, which was kind of overwhelming, very long, 
we met at five and we came home at five in the morning, we went to the sea, we made a bonfire. [...] I had never seen so many bisexual people before and I was also very happy there.

(Irene, 32, bisexual cis woman; my italics)

For Guido, too, the community represented a safe space in which to explore their identity:

In the community I found some friends, some real friends, I found the community very cool because [...] the people I found were part of the process of feeling myself in the possibility of being ... who I want, therefore also the possibility of being in a space [...] in which to prove to be a different person: The first time I wore a dress was here, the first time I said it openly to a person who was not in the group was here, I feel safer here too, because they know me, because they have always seen me ... it's a safe space for me.

(Guido, 30, pansexual genderfluid)

These findings confirm the importance of involvement in non-normative communities (Gusmano, 2018). Monro (2015) recognises this as a function of bisexual communities too. Three people within my subsample were bisexual activists, but neither they nor any of the other participants mentioned the bisexual community as having this specific function. This absence can be traced back to the fact that my interviews were focusing on the polyamorous community, but I also hypothesise that in the absence of a strong and deep-rooted bisexual community, some plurisexual people found the polyamorous community to be a place where they could express themselves (cf. Gusmano, 2018).

However, not all the interviewees perceived the polyamorous community as strongly bisexual:

Marta: In the poly community [...] there isn't much ... flexibility, I think ... at least in the group in [city] ...

Nicole: $\mathrm{Mm}$... flexibility, you say ... er ... bisexual people, or ...?

Marta: Bisexual people. I don't ... there don't seem to be many. I mean, they do it at the level of ... erotic games, right? [...] In short, maybe at sex parties, but always oriented within their relationships with their [male] partners ... always in that perspective there, that sincerely, to me ... I don't care. I take it individually.

(Marta, 42, pansexual cis woman)

Unlike Irene, Marta did not seem to have found many bisexual people within the polyamorous community. On closer inspection, however, her judgement about women in the community who called themselves bisexual may have 
been the effect of internalised bi-erasure that led her to consider only a restricted category of people/behaviours as "truly bisexual" (cf. Maliepaard, 2017). Indeed, she thought that these women's bisexual performance was a function of the male gaze (cf. Maliepaard, 2017; Monro, 2015).

\section{Challenging polynormativity and binormativity}

The intersection between plurisexualities and non-monogamies represents a challenge to both monosexism and compulsory monogamy, precisely because these two identities (and/or the practices they refer to) are perceived as threatening to the social order (Cruz, 2014; Gusmano, 2018; Mint, 2004). This section discusses the challenges that this intersection also represents with respect to binormativity and to polynormativity.

Both bisexual and polyamorous communities seem to prioritise love discourses over sex discourses to make bisexuality and non-monogamy more acceptable to mainstream society. This tendency to exclude the most "unpresentable" actors from sexual minority communities can be connected to the functioning of what Rubin (1992) calls the "sexual hierarchy". According to the dominant sexual hierarchy in Western societies, the sexualities considered " 'good', 'normal' and natural" are "heterosexual, marital, monogamous, reproductive, and non-commercial" (Rubin, 1992, p. 152). All other sexualities are considered "'bad', 'abnormal', or 'unnatural'" (1992, p. 152). This hierarchy generates struggles between different groups based on "how to draw the line" (Rubin, 1992, p. 152) between good and bad sexualities. This is the reason why contemporary mainstream LGBT activism struggles to cleanse its image of allegations of promiscuity, perversion, infidelity, and commercial sex. Polynormativity and binormativity seem to follow the same mechanism: They are both defensive strategies that aim for the normalisation of polyamorous and bisexual people respectively.

Some of my interviewees also insisted on establishing a distance between polyamory and infidelity, or from other consensual non-monogamies such as swinging and casual sex. For example, Eleonora (32) and Gabriele (27) told me that they had not enjoyed a polyamorous event organised by the small local community because "true polyamorous could be counted on the fingers of one hand", implying that all the other people had been adulterers or swingers. These two participants reiterated several times during the interview that their love was "true love".

Looking at the intersection of plurisexual and non-monogamous identities (and/or practices) from a radical point of view means looking for the transformative potential of this intersection. In affirming this I do not mean that all plurisexual and non-monogamous people are subversive and revolutionary, but I intend to accept Eisner's (2013) suggestion that we take advantage of the threatening potential that bisexuality and non-monogamy represent to stimulate social change. 


\section{Nicole Braida}

Manuel's account of his own path towards self-determination is useful to deepen this reflection:

My great gripe was ... when I fell in love with someone, to convince him that I wasn't ... a slut [...], I had to enter the position of having to prove my love, to demonstrate ... to deny my past and even, at some point, to deny stereotypes, such as a bisexual person cannot be monogamous. So, I was fighting against this stereotype, until at some point I said to myself: 'But do you know what it is? True, a bisexual person can be monogamous, but that's not my case'. [We laugh.] And, therefore, I don't know, I saw it as a moment of great liberation. [...] Then, when I later declared myself a slut, eager, an intellectual snob and so ... like maybe the first relationship I had after this moment, saying: 'I feel balanced, and I feel that my gender dysphoria right now - then who knows? - is appeased by the fact of being with [a female partner and a male partner]'.

(Manuel, 32, bisexual non-binary trans man)

Manuel reflects on how he first tried to conform to binormative expectations, denying that he was promiscuous and non-monogamous, and denying that he needed a man and a woman at the same time. But then he realised that in that specific phase of life he had attained balance by dating a woman and a man at the same time, and that this was his personal experience, and therefore valid and worthy.

However, it is also important to highlight that publicly assuming identities that challenge the dominant order is not a position that is accessible to everyone, especially in some spheres of life such as the work environment (where, in fact, most of my respondents were not out). Popova (2018) found that bisexuality could remain silent and invisible - and therefore acceptable - in a workplace context until it touched on the sphere of identity. On the other hand, when it was accompanied by a polyamorous practice, bisexuality fell out of the ranks of respectability and was more difficult to encompass within institutional structures.

Coming out is also difficult for people who live with their parents - a not uncommon situation in Italy, where precarious working conditions are accompanied by a familialist welfare regime (cf. Gusmano, 2018).

\section{Discussion and concluding remarks}

My exploration of theories and practices of consensual non-monogamy in Italy confirms that there is a strong interconnection between plurisexualities and consensual non-monogamous practices. For many of my participants, the two identities or practices went hand in hand, and for some people polyamorous theories and practices were an incentive to explore plurisexualities too. Above all, this intersection seems to stimulate the overcoming of 
rigid and mutually exclusive dichotomies (especially homosexual/heterosexual, woman/man, and love/not love). For some people (although not for everyone), the polyamorous community represented a safe space in which to experiment with both. The lack of evidence of a bisexual community here highlights that, at the time of the interviews, my participants did not perceive the bisexual community in Italy as a concrete and traversable space (for example, support and discussion groups for bisexual people were currently present in very few cities).

Outside these protected areas, the intersection of the two identities/ practices often gives rise to the amplification of stigma, which is particularly hard to manage for the most vulnerable subjects, and which applies even in LGBT spaces. It is important, however, to grasp and highlight the transformative and subversive potential of this intersection. Indeed, it also contains the potential to challenge some of the defensive strategies of the reference communities themselves, particularly those that tend towards normalisation and victimisation. The figures of the "good homosexual" (Klesse, 2007, p. 12), the "good polyamorous" (cf. Ferrer, 2018; Ritchie, 2010), or the "good bisexual" (Eisner, 2013, p. 43) remove stigma only from those who adapt to the status quo, but they weaken the transformative power of struggles, strengthening dominant mononormative and heteronormative narratives (cf. Klesse, 2006, 2016).

Hopefully, the unveiling of the conflicts and drawbacks of these strategies may inspire the different communities to move towards convergence. In this sense, one of the common aims may be the reappropriation and affirmation of diversity through conflict with different types of normativity.

\section{Notes}

1 My project began with a strong focus on polyamorous theories, practices, and communities. Nevertheless, I prefer to use this more inclusive term, since many of my participants did not identify as polyamorous, and some (especially those who identified as relationship anarchists) criticised the polyamorous approach because in their opinion it did not question the hierarchy between romantic and non-romantic relationships.

2 Relationship anarchy can be defined as the practice of forming relationships that are not bound by rules other than those mutually agreed by the people involved. It differs from polyamory because it is more radically non-hierarchical and refuses to apply labels to relationships, such as "just friends", "in a relationship", and so on (cf. Anapol, 2010).

3 In the interview extracts, “..." indicates a break in speech, while "[...]" indicates a deletion from the original transcript.

\section{References}

Anapol, D. (2010). Polyamory in the 21st century: Love and intimacy with multiple partners. Lanham, MD: Rowman and Littlefield. 


\section{Nicole Braida}

Ault, A. (1994). Hegemonic discourse in an oppositional community: Lesbian feminists and bisexuality. Critical Sociology, 20(3), 107-22. doi: 10.1177/ 089692059402000306

Baumgartner, R. (2017). “I think I'm not a relationship person”: Bisexual women's accounts of (internalised) binegativity in nonmonogamous relationship narrative. Psychology of Sexualities Review, 8(2), 25-40.

Cooper, B. (2016). Intersectionality. In L. Disch \& M. Hawkesworth (Eds.), The Oxford handbook of feminist theory (pp. 385-406). New York: Oxford University Press. doi: 10.1093/oxfordhb/9780199328581.013.20

Cruz, E. (2014). 13 lies we have to stop telling about bisexual people. Retrieved from http://everydayfeminism.com/2014/10/13-lies-about-bisexuals

Del Castillo, V.D. \& Review, T.N.B. (2015). Regulating bisexuality: Binormativity and assimilation to the homonormative order in American scripted television series. The New Birmingham Review, 2(1), 10-22.

Eisner, S. (2013). Bi: Notes for a bisexual revolution. Berkeley, CA: Seal Press.

Ferrer, J.N. (2018). Mononormativity, polypride, and the "Mono-Poly Wars". Sexuality and Culture, 22(3), 817-36. doi: 10.1007/s12119-017-9494-y

Guba, E.G. \& Lincoln, Y.S. (1994). Competing paradigms in qualitative research. In N.K. Denzin \& Y.S. Lincoln (Eds.), Handbook of qualitative research (pp. 10517). Thousand Oaks, CA: Sage.

Gurevich, M., Bower, J., Mathieson, C.M. \& Dhayanandhan, B. (2007). 'What do they look like and are they among us?' Bisexuality, (dis)closure and (un)viability. In V. Clarke, \& E. Peel (Eds.), Out in psychology: Lesbian, gay, bisexual, trans, and queer perspectives (pp. 217-42). Chichester: Wiley.

Gusmano, B. (2018). Coming out through an intersectional perspective: Narratives of bisexuality and polyamory in Italy. Journal of Bisexuality, 18(1), 15-34. doi: 10.1080/15299716.2017.1416510

Gustavson, M. (2009). Bisexuals in relationships: Uncoupling intimacy from gender ontology. Journal of Bisexuality, 9(3/4), 407-29. doi: 10.1080/ 15299710903316653

Keso H., Lehtimäki H. \& Pietiläinen T. (2009). Engaging in reflexive acts: Sharing experiences on reflexivity in empirical qualitative research. Tamara Journal, 7(3), 51-70.

Klesse, C. (2005). Bisexual women, non-monogamy and differentialist anti-promiscuity discourses. Sexualities, 8(4), 445-64. doi: 10.1177/1363460705056620

Klesse, C. (2006). Polyamory and its "others": Contesting the terms of nonmonogamy. Sexualities, 9(5), 565-83. doi: 10.1177/1363460706069986

Klesse, C. (2007). The spectre of promiscuity. Gay male and bisexual non-monogamies and polyamories. Aldershot: Ashgate.

Klesse, C. (2011). Shady characters, untrustworthy partners, and promiscuous sluts: Creating bisexual intimacies in the face of heteronormativity and biphobia. Journal of Bisexuality, 11(2/3), 227-44. doi: 10.1080/15299716.2011.571987

Klesse, C. (2016). Marriage, law and polyamory. Rebutting mononormativity with sexual orientation discourse? Oñati Socio-legal Series, 6(6), 1348-76.

Maliepaard, E. (2017). Bisexuality in the Netherlands: Connecting bisexual passing, communities, and identities. Journal of Bisexuality, 17(3), 325-48. doi: 10.1080/ 15299716.2017.1342214

McLean, K.E. (2008). Silences and stereotypes: The impact of (mis)constructions of bisexuality on Australian bisexual men and women. Gay and Lesbian Issues and Psychology Review, 4(3), 158-65. 
Meyer, I.H. (2003). Prejudice, social stress, and mental health in lesbian, gay, and bisexual populations: Conceptual issues and research evidence. Psychological Bulletin, 129(5), 674-97. doi: 10.1037/0033-2909.129.5.674

Mint, P. (2004). The power dynamics of cheating: Effects on polyamory and bisexuality. Journal of Bisexuality, 4(3/4), 55-76. doi: 10.1300/J159v04n03_04

Monro, S. (2015). Bisexuality: Identities, politics and theories. London: Palgrave Macmillan.

Ochs, R. (1996). Biphobia: It goes more than two ways. In B.A. Firestein (Ed.), Bisexuality: The psychology and politics of an invisible minority (pp. 217-39). London: Sage.

Ochs, R. \& Rowley, S.E. (2009). Getting bi. Voices of bisexuals around the world. Boston, MA: Bisexual Resource Center.

Page, E.H. (2004). Mental health services experiences of bisexual women and bisexual men: An empirical study. Journal of Bisexuality, 4(1/2), 137-60. doi: 10.1300/ J159v04n01_11

Plummer, L. (1995). Telling sexual stories: Power, change and social worlds. London: Routledge.

Popova, M. (2018). Inactionable/unspeakable: Bisexuality in the workplace. Journal of Bisexuality, 18(1), 54-66. doi: 10.1080/15299716.2017.1383334

Rambukkana, N.P. (2004). Uncomfortable bridges. Journal of Bisexuality, 4(3/4), 141-54. doi: 10.1300/J159v04n03_11

Ritchie, A. (2010), Discursive constructions of polyamory in mono-normative media culture. In M. Barker \& D. Langdridge (Eds.), Understanding non-monogamies (pp. 46-51). New York: Routledge.

Robinson, M. (2013). Polyamory and monogamy as strategic identities. Journal of Bisexuality, 13(1), 21-38. doi: 10.1080/15299716.2013.755731

Rubin, G. (1992). Thinking sex: Notes for a radical theory of the politics of sexuality. In C.S. Vance (Ed.), Pleasure and danger: Exploring female sexuality (pp. 26793). London: Pandora.

Rust, P.C. (2003). Monogamy and polyamory: Relationship issues for bisexuals. In L. Garnets \& D.C. Kimmel (Eds.), Psychological perspectives on lesbian, gay, and bisexual experiences (pp. 475-96). New York: Columbia University Press.

Simon, W. (1996). The postmodernization of sex. In W. Simon (Ed.), Postmodern sexualities (pp. 17-37). London: Routledge.

Toft, A., \& Yip, A.K.T. (2018). Intimacy negotiated: The management of relationships and the construction of personal communities in the lives of bisexual women and men. Sexualities, 21(1-2), 233-50. doi: 10.1177/1363460716679793

Wilkinson, E. (2010). What's queer about non-monogamy now? In M. Barker \& D. Langdridge (Eds.), Understanding non-monogamies (pp. 243-54). New York: Routledge.

Wilkinson, E. (2013). Learning to love again: "Broken families", citizenship and the state promotion of coupledom. Geoforum, 49, 206-13. doi: 10.1016/ j.geoforum.2013.02.012 